\section{AMISULPRIDE VERSUS RISPERIDONE IN THE TREATMENT OF ACUTE EXACERBATION OF SCHIZOPHRENIA}

\author{
Ranjan $\mathrm{S}^{\star}$, Vyas J.N ${ }^{* \star}$
}

*Associate Professor, Department of Psychiatry, U.C.M.S. Teaching Hospital, Ranigaon, Bhairahawa, Nepal

${ }^{* *}$ Professor, National Medical College, Birgunj, Nepal

Address for Correspondence:-

Dr. Sanjeev Ranjan, Associate professor, Department of Psychiatry U.C.M.S. Teaching Hospital, Ranigaon, Bhairahawa, Nepal

Email: drsanjeevranjan@yahoo.com

\begin{abstract}
Introduction: Amisulpride and risperidone are both atypical antipsychotic having different receptor affinity characteristics. Although there are many studies comparing the efficacy of both drugs with conventional antipsychotics, studies comparing the efficacy of amisulpride with risperidone are less. There are no such studies published till yet from Nepal. This study aims to compare the efficacy and safety of amisulpride with that of risperidone in patients with acute exacerbation of schizophrenia in Nepal.
\end{abstract}

Methods: 100 patients with acute exacerbation of schizophrenia were randomly put on flexible dose of amisulpride (200-1000mg/day) or risperidone (2-10mg/day) for six weeks after three to six day placebo wash-out period. Efficacy was assessed by changes in score of Brief Psychiatry Rating Scale (BPRS). Safety assessment was done by adverse event reporting, physical examination, blood pressure, heart rate monitoring and applying modified Simpson-Angus Scale for extra pyramidal symptoms.

Results: Most of the patients in both group responded equally to medication. $84 \%$ of amisulpride receiving patients versus $86 \%$ in risperidone group responded to treatment. Both drugs were safe and caused comparable extra pyramidal symptoms (amisulpride/risperidone: 14/16). However, risperidone caused more weight gain than amisulpride $(64 \%$ vs. $12 \%)$.

Conclusion: Amisulpride and risperidone are equally effective in the treatment of acute exacerbation of schizophrenia. Both drugs were well tolerated. Amisulpride was associated with less weight gain.

Key words: - Amisulpride, Risperidone, Acute exacerbation of schizophrenia

\section{INTRODUCTION}

Risperidone is a serotonin dopamine antagonist. It is a highly effective agent for positive symptoms of schizophrenia, and it also improves negative symptoms better than 
conventional

antipsychotics.

Amisulpride is classified under the category of atypical antipsychotic as risperidone. However, it has different action as compared to risperidone. Amisulpride is a dopamine partial agonist at D2 receptor (DPA) with no affinity for serotonin $2 A$ or $1 A$ receptors. ${ }^{1}$

Studies in patients with acute exacerbations of schizophrenia have shown that amisulpride is as effective as haloperidol and Flupenthixol in treating positive symptoms with additional effects on negative symptoms compared with haloperidol. Amisulpride was also found to have good safety and tolerability profile, with fewer extra pyramidal symptoms (EPS) than conventional antipsychotics and a low incidence of weight gain. ${ }^{2}$

Regarding safety profile, risperidone is better tolerated than conventional antipsychotics in terms of extra pyramidal side effects. $^{2}$ However, at higher doses, it can cause extra pyramidal side effects. There is less weight gain with risperidone than with some other atypical antipsychotic agents. ${ }^{1}$

Comparative data on atypical antipsychotics is needed to optimize their clinical use. There are few studies comparing the efficacy and safety of amisulpride and risperidone in schizophrenia. Most of the study showed amisulpride to be as effective as risperidone. Amisulpride was associated with less weight gain and in some studies with less EPS than risperidone. ${ }^{2}$ So this study was undertaken to compare amisulpride with risperidone in the treatment of acute exacerbation of schizophrenia.

\section{METHODS}

This was hospital-based, prospective, follow-up study carried out in the tertiary care hospital of mid-eastern region of Nepal. One hundred patients, both male and female, diagnosed as schizophrenia according to International Classification of Diseases (ICD-10), with acute exacerbation attending the psychiatry department of National Medical College were included.

Inclusion Criteria:

Patients aged between 15 to 60 years who fulfilled the diagnostic criteria of Schizophrenia according to ICD-10, with acute exacerbation of symptoms were included in this study. Only the patients whose relatives or caretaker had given written consent to participate in this study were included.

\section{Exclusion Criteria:}

Patients having gross organic brain disorders, symptoms of substance related withdrawal, severe medical illness, mental retardation, past history of non-response to at least two wellvalidated antipsychotics, and the patients who have been on continuous antipsychotic treatment for more than one week immediately prior to our contact were excluded from the study. Uncooperative patients, pregnant or breast feeding women were also excluded from the study. 
Half of the patients were randomly started on flexible dose of amisulpride (200-1000mg/day) and the remaining half on risperidone (2-10mg/day) following a three- to six-day placebo wash-out period. Patients were followed up for six weeks. Patients who showed more than $20 \%$ improvement on the BPRS total score during the placebo washout period were excluded from the study. The doses were set at a ratio of $1 \mathrm{mg}$ risperidone to $100 \mathrm{mg}$ amisulpride. Patients were prescribed benzodiazepines for sleep and trihexyphenidyl for EPS. No other psychotropic medication was prescribed during the study.

Brief psychiatric rating scale (BPRS) was applied before starting medicine, and then at seven day interval till six weeks. Improvement was assessed as per the verbal report of the patient and his attendant and by improvement in BPRS.

Brief Psychiatric Rating Scale (BPRS) is principally used as an outcome measure in treatment studies of schizophrenia and other psychotic illness. Reliability of the BPRS is good to excellent when raters are experienced ${ }^{3}$. Validity is also good $^{3}$. This scale has frequently been used by the rater. Its English version was first translated into Nepali by English to Nepali translator and the translated Nepali version was again translated into English by independent translator. This scale was first applied in other patients and was found to be effective. Patient's vital signs, physical examination and body weight was regularly monitored. Modified Simpson Angus Scale was applied to assess for extrapyramidal symptom.

Ethical consideration:

Ethical clearance was taken from the institute before conducting the study. Verbal and written consent of the patients or his attendants were taken before enrolling them in the study.

This study was carried out from $1^{\text {st }}$ August 2011 to $31^{\text {st }}$ July 2012.

\section{RESULTS}

Out of the fifty patients receiving risperidone, forty three $(86 \%)$ of them showed good response in their symptoms, whereas 7 patients (14\%) showed poor response (less than fifty percent improvement) to treatment. Among amisulpride receiving patients, forty two patients (84\%) showed good response to treatment. Eight patients $(16 \%)$ had poor response to treatment.

\section{TABLE 1. Efficacy of amisulpride compared to risperidone}

\begin{tabular}{|l|l|l|}
\hline & Amisulpride & Risperidone \\
\hline $\begin{array}{l}\text { Good } \\
\text { response }\end{array}$ & $42(84 \%)$ & $43(86 \%)$ \\
\hline $\begin{array}{l}\text { Non } \\
\text { response }\end{array}$ & $8(16 \%)$ & $7(14 \%)$ \\
\hline
\end{tabular}

At $\mathrm{df}=1$, and $\mathrm{p}=0.05$ chisquare tabulated value was 3.841 , whereas our calculated chisquare value was 0.0777 . So this difference in efficacy was not statistically significant.

Sixteen patients (32\%) receiving risperidone had clinically significant degree of movement disorders, with Modified Simpson-Angus Scale (MSAS) score more than five. Two patients $(4 \%)$ had minimal degree of movement disorder, with MSAS score ranging from three to five. In the 
amisulpride group, fourteen patients $(28 \%)$ had clinically significant movement disorder. Five patients $(10 \%)$ had minimal degree of movement disorder.

TABLE 2. Comparison of amisulpride and risperidone side effects profile

\begin{tabular}{|l|l|l|l|l|}
\hline & \multicolumn{2}{|l|}{$\begin{array}{l}\text { Extrapyramid } \\
\text { al symptoms }\end{array}$} & \multicolumn{2}{l|}{$\begin{array}{l}\text { Weight } \\
\text { gain }\end{array}$} \\
\cline { 2 - 5 } & $\begin{array}{l}\text { Pres } \\
\text { ent }\end{array}$ & $\begin{array}{l}\text { Absen } \\
\text { t } \\
\text { (or } \\
\text { minim } \\
\text { al) }\end{array}$ & $\begin{array}{l}\text { Pre } \\
\text { sen } \\
\text { t }\end{array}$ & $\begin{array}{l}\text { Abs } \\
\text { ent }\end{array}$ \\
\hline $\begin{array}{l}\text { Amisu } \\
\text { Ipride }\end{array}$ & 14 & 36 & 6 & 44 \\
\hline $\begin{array}{l}\text { Risper } \\
\text { idone }\end{array}$ & 16 & 34 & 32 & 18 \\
\hline
\end{tabular}

Weight gain was considered to be significant if there was more than five percent increase in body weight after one month of start of medicine. Thirty two patients $(64 \%)$ in risperidone group had more than five percent body weight gain from the baseline. On the other hand, in amisulpride group, only six patients $(12 \%)$ had significant weight gain. (Table 2) The tabulated chiquare value for $d f=1$ at $p=0.05$, is $x^{2}=3.841$ which is greater than calcutaed $x^{2}=28.69$, so this difference in increase in body weight among amisulpride and risperidone was statistically significant.

There were no clinically relevant changes in vital signs in either group.

\section{DISCUSSION}

The above result shows that amisulpride is as effective as risperidone in the treatment of acute exacerbation of schizophrenia. Many studies comparing amisulpride with risperidone in schizophrenia have also shown similar result. 2,4,5,6 However, study done by Peuskens $\mathrm{J}$ et al. showed that though both treatments produced a marked improvement in schizophrenic symptomatology. All the individual factors on BPRS showed a numerically greater improvement in the amisulpride than in the risperidone patients. $^{7}$

In our study, both drugs were well tolerated and there was not much difference in the incidence of developing EPS in both groups (amisulpride/risperidone: $28 \% / 32 \%$ ). This finding was in accordance with findings from other studies. $2,4,6,7$

Regarding weight gain, in our study significant number of patients receiving risperidone had weight gain compared to amisulpride $(64 \%$ vs $12 \%)$. Our study supports similar findings got from other studies. ${ }^{2,6,7}$

There was no clinically relevant change in blood pressure, heart rate in both amisulpride and risperidone group, as shown in other studies. ${ }^{2}$ Study done by Hwang $\mathrm{TJ}$ et al. showed that patients receiving amisulpride had reduction of blood pressure and heart rate. Although statistically significant, this finding was not found to be clinically significant. ${ }^{6}$ 


\section{CONCLUSION}

This study suggests that amisulpride is as effective as risperidone in the treatment of acute exacerbation of schizophrenia. Both drugs are well tolerated and has similar propensity to induce extra pyramidal symptoms. There is greater risk of weight gain with risperidone compared to amisulpride.

\section{DECLARATION OF INTEREST:}

None.

\section{REFERENCES}

1. Stahl's Essential Psychopharmacology. Third edition. Editor- Stephen M. Stahl. Publisher- Cambridge university press. $P$ : 412-423.

2. Sechter D, Peuskens J, Fleurot O, Rein $W$, Lecrubier $Y$ and Amisulpride Study Group. "Amisulpride vs. Risperidone in Chronic Schizophrenia: Results of a 6-month Double-blind Study." Neuropsychopharmacology. 2002 Dec; 27(6):1071-81.

3. Blacker $D$. Psychiatric Rating Scales. In: Sadock JB, and Sadock AV, editors. Comprehensive Textbook of Psychiatry. $8^{\text {th }}$ Edition. Lippincott Williams \& Wilkins; 2005. p. 938-43.

4. Riedel M, Eich FX, Moller HJ. "A pilot study of the safety and efficacy of amisulpride and risperidone in elderly psychotic patients." Eur Psychiatry. 2009 Apr; 24(3):149-53.

5. Muller HJ. "Amisulpride: a review of its efficacy in schizophrenia." Acta Psychiatr Scand Suppl. 2000;400:17-22.

6. Hwang $T J$, Lee $S M$, Sun $H J$, Lin HN, Tsai SJ, Lee YC et al. "Amisulpride versus risperidone in the treatment of schizophrenia patients: a double-blind pilot study in Taiwan." J Formos Med Assoc. 2003 Jan;102(1):30-6.

7. Peuskens J, Bech P, Moller $\mathrm{HJ}$, Bale R, Fleurot O, Rein W. "Amisulpride vs. risperidone in the treatment of acute exacerbation of schizophrenia. Amisulpride study group." Psychiatry Res. 1999 Nov 8; 88(2):107-17. 